\title{
DESENVOLVIMENTO DE SOFTWARE PARA GESTÃO DE OVINOS
}

\author{
DEVELOPMENT OF SOFTWARE FOR SHEEP MANAGEMENT
}

Lucas Mangelo Fernandes - lucas.mangelo@yahoo.com.br

Anna Patricia Zakem China - apzchina@gmail.com

Faculdade de Tecnologia de Ribeirão Preto (Fatec) - Ribeirão Preto - São Paulo - Brasil

DOI: 10.31510/infa.v17i1.806

\section{RESUMO}

Este artigo visa apresentar o desenvolvimento de um software que pretende atender todas as necessidades do produtor de ovinos, contempla os principais manejos que são de grande importância para o acompanhamento e criação do animal. Apresenta os processos de cuidados com ovinos, as escolhas tecnológicas realizadas para a criação de um produto com foco na experiência do usuário, com uma interface gráfica fácil e acessível para o produtor rural. A solução apresentada, busca ser uma ferramenta para identificar a evolução do rebanho, sendo assim possibilitar a redução de custos e aumento da produtividade, bem como aplicar a rastreabilidade do animal em todo o seu ciclo de vida.

Palavras-chave: Gestão. Software. Manejo de Ovinos.

\begin{abstract}
This article aims to present a software development that intends to serve all the needs of sheep producers, it contemplates the main phases that are of great importance for monitoring and raising the animal. It presents the processes of sheep care, the technological choices made to create a product that focuses on the user experience, with an easy to use graphic interface and accessible to rural producers. The solution presented seeks to be a tool to identify the evolution of the herd, thus making it possible to reduce costs and increase productivity, as well as apply traceability of the animal in all its life circle.
\end{abstract}

Keywords: Management. Software. Sheep Handling.

\section{INTRODUÇÃO}

O agronegócio é de fato uma área de extrema importância para a economia do país e vem recebendo atenção para novas soluções tecnológicas que auxiliam em vários aspectos o produtor rural, seja para corte de custos e aumento da produtividade, como para melhorar o controle e gestão do seu negócio. 
Observando este grande movimento de expansão, foi identificado por Raineri et al (2013) que a ovinocultura é carente por programas que compreendem todos os requisitos para a gestão que o ovinocultor precisa para extrair o máximo de lucratividade de seu rebando.

Com isso, este artigo busca apresentar o desenvolvimento de um software que atenda este mercado e resolva um dos grandes problemas na ovinocultura que é falta de rastreabilidade de animais. Segundo Lirani (2007), refere-se à possibilidade de obter um histórico do animal, sobre informações de onde esteve, sua alimentação, por quais tratamentos foi submetido, ou seja, é necessário coletar dados que permeiam todo o seu ciclo de vida. O autor ainda ressalta que para alcançar o produto de qualidade, uns dos primeiros passos é ser rastreável.

É de interesse apresentar as tecnologias utilizadas na construção do software, bem como as decisões tomadas para o alcance do objetivo. Sendo elas, Angular e Electron para o frontend, ASP.NET Core para o back-end e PostgreSQL como banco de dados relacional.

\section{FUNDAMENTAÇÃO TEÓRICA}

Após a concepção da ideia da construção de uma nova solução, foi necessário o entendimento do mercado de ovinos no Brasil e os processos de criação destes animais.

\subsection{Ovinocultura no Mundo e no Brasil}

Segundo Viana (2008), os ovinos foram uma das primeiras espécies a serem domesticadas pelo homem. Tais animais são criados para o consumo de carne e de leite e para a produção de lã. Atualmente a produção ovina está destinada a exploração econômica e para subsistência de famílias.

A ovinocultura está presente em quase todos os continentes, esses animais possuem a característica de se adaptar a diversos climas, relevos e vegetações. Os maiores rebanhos estão presentes na Ásia, África e Oceania, sendo a China o país líder de número de animais, seguido da Austrália, Índia, Irã, Sudão e Nova Zelândia (VIANA, 2008).

Os países Austrália e Nova Zelândia são conhecidos por terem uma alta produtividade de ovinos, tudo isso se deve a criação altamente técnica, visando a produção de carne e de lã, a qual, leva o controle do mercado internacional do produto (VIANA, 2008). 
De acordo com o IBGE (2018), no Brasil há cerca de 18,9 milhões de cabeças de ovinos distribuídas por todo o país, concentrada principalmente no estado do Rio Grande do Sul e na região nordeste. Segundo Viana (2008), no Rio Grande do Sul há interesse nas raças de carne, laneiras e mistas, nos quais são adaptadas ao clima subtropical, há maior investimento na criação de carne e de lã. A região nordeste foca na criação de carnes e peles através das raças deslanadas, adaptadas ao clima tropical.

Viana (2008) ressalta que no Nordeste houve uma significante melhora na produtividade e exploração econômica da ovinocultura. Foram realizados melhoramentos genéticos, introduções de raças especializadas e aplicações de técnicas de manejo. Apesar da melhora, segundo SEBRAE (2009) o Nordeste é mais caracterizado pela criação de ovinos por subsistência do que para o sistema produtivo.

SEBRAE (2009) ressalta que a produção de carne se tornou o principal objetivo da ovinocultura e apresenta preços elevados ao produtor e assim tornou o mercado de criação de ovinos atraente, resultando no aumento de número de animais abatidos no Brasil. Mas, apesar do crescimento, o Brasil realiza importações de carne ovina para suprir a necessidade do mercado consumidor, visto que a oferta interna não é suficiente.

\subsection{Manejo Reprodutivo}

Segundo o SEBRAE (2009), o manejo reprodutivo de animais possui grande influência no desempenho produtivo do rebanho, por isso é de grande importância seguir corretamente técnicas e um conjunto de práticas para melhor desempenho de produção.

O cuidado inicia com a escolha de animais aptos para a reprodução, sejam estes animais adquiridos através de outros produtores ou mesmo nascidos e incorporados no próprio rebanho que foram destinados a reprodução (SEBRAE, 2009).

A seleção de machos reprodutores é feita através de exames físicos como a medição de testículos para análise de fertilidade. Além disso, o histórico de seus descendentes e sua idade são de grande valor ao considerar o animal para reprodução (SEBRAE, 2009).

A escolha de matrizes, ou seja, ovelhas mães que são destinadas para reprodução, é peça chave no desempenho reprodutivo. Para estes animais é preciso observar uma série de aspectos como suas características maternas, se é dócil para o manejo e seu histórico de doenças. Assim como o reprodutor, o histórico de parição é de grande importância, pois é necessário identificar 


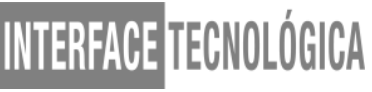

possíveis abortos, quantidade de parições e o desempenho de suas crias após o parto até a desmama (SEBRAE, 2009).

\subsection{Manejo Sanitário}

De acordo com $\operatorname{SEBRAE}^{1}$ (2009), o manejo sanitário visa um conjunto de técnicas utilizadas pelo ovinocultor para diminuir ou evitar o contágio de doenças no seu rebanho, a fim de minimizar os prejuízos na criação de seus animais.

As práticas de higiene e profilaxia são de grande importância para manter a saúde dos animais, tornando-os mais produtivos ao prevenir e controlar doenças. O SEBRAE (2009) recomenda que seja realizada a limpeza do aprisco regularmente, sendo necessária a higienização diária de bebedouros e comedouros, eliminando restos de comidas. Também, aconselha-se a desinfecção mensal das instalações com creolina ou vassoura-de-fogo.

É preciso que o produtor fique atento aos sinais apresentados pelos animais, como a isolação do restante do rebanho, falta de apetite, má qualidade ou queda de pelos, temperatura corporal acima de $40^{\circ} \mathrm{c}$, dentre outras características. A rápida identificação de animais com início de alguma doença pode evitar o contágio para outros animais e melhor recuperação do mesmo (SEBRAE, 2009).

\section{MATERIAIS E MÉTODOS}

Com o intuito de utilizar a metodologia aplicada para análise dos resultados obtidos e consequentemente, obter um melhor desenvolvimento e execução do software a ser construído, foi analisado o cenário de criação ovinos, bem como o processo de aproveitamento de seus produtos (lã, carne e leite) e as reais necessidades do produtor para gestão de seu negócio.

O desenvolvimento do software foi estruturado na metodologia ágil Scrum. De acordo com Terlizzi e Biancolino (2014), consiste em um framework estrutural conceituado como uma metodologia ágil fundamentada no empirismo, em que o conhecimento é adquirido através das experiências e tomadas de decisões. Possui três pilares fundamentais: transparência, inspeção e 
adaptação. Estes princípios visam a melhora na comunicação do time de desenvolvimento, identificação de problemas e oportunidades.

Segundo Bellenzier (2017), a metodologia Scrum possui ciclos regulares chamados Sprint representados por um timebox, ou seja, um intervalo de duas a quatro semanas, na qual é planejado e executado um conjunto de tarefas neste período. Com isso, a cada novo ciclo foi possível identificar os principais recursos para desenvolvimento do produto.

\subsection{Análise de Requisitos}

A concepção da criação do software surgiu por meio da análise do mercado atual de ovinos, identificando o déficit de soluções que inovem e tragam reais ganhos para o produtor. Após analisar as soluções oferecidas no mercado como, Sistema de Gerenciamento de Rebanhos da Embrapa e Sistema Ovinos, foi possível identificar as escolhas técnicas que inviabilizaram o sucesso na aplicabilidade do produto construído:

a) Dependência constante de conexão de internet por parte do usuário: Apesar de toda a melhoria nos meios de comunicação no âmbito rural, há ainda limitações de infraestrutura para um ambiente estável. Através desta característica, a melhor escolha para distribuição do software foi por meio de uma aplicação desktop, sem dependência de conexão constante.

b) Interface gráfica não intuitiva e confusa para o público alvo: Uma vez que o público alvo são produtores, que muitas vezes não possuem familiaridade com tecnologia e produtos eletrônicos, mas são pessoas que possuem interesse em constante melhoria em seu processo de produção. Ao diagnosticar essa particularidade, uns dos objetivos principais foi desenvolver uma solução com interface gráfica clara e amigável, aplicando um grande foco na usabilidade e experiência do usuário.

\subsection{Tecnologias Utilizadas}

Mediante as situações acima descritas, optou-se pelo desenvolvimento de software desktop, o qual é envolto por várias tecnologias consolidadas no mercado, tais como Windows Forms da Microsoft, Java e o menos conhecido Tkinter com a linguagem Python. Todas são nativas e conseguem acessar recursos do Sistema Operacional (SO), como diretórios e arquivos. 
Além das dificuldades relacionadas à inviabilidade de outros produtos, a escolha da tecnologia para a construção do software foi decidida após análise do tempo para a curva de aprendizagem de modo a extrair seu verdadeiro potencial. Ademais, foi considerado o foco na construção da melhor interface gráfica para proporcionar uma boa experiência para o usuário.

As características de interfaces desejadas para o programa combinavam com as soluções já existentes na Web e com o HTML (Hyper Text Markup Language), CSS (Cascading Syle Sheets) e Javascript. O conjunto destas tecnologias possibilita customizar livremente e proporciona a construção de um sistema responsivo, facilitando o uso em dispositivos de diversas resoluções. Com isso, foram identificadas duas bibliotecas distribuídas em Node.js, os quais são Angular e Electron.

O Angular é um framework reativo orientado a estrutura Model-View-Controller (MVC), no qual, segundo Alves (2019) refere-se à separação do sistema em camadas de visualização, modelagem de dados e de controle. Sendo possível definir a responsabilidade de cada parte desta estrutura, auxiliando na manutenção e evolução do sistema. Outra característica citada por Alves (2019) é a sua capacidade de criar aplicações Single-Page Applications (SPA), ou seja, uma única página principal, com as demais sendo carregadas em áreas específicas, esse conceito proporciona uma experiência fluída de transição entre páginas diferentes, aspecto semelhante com as soluções desenvolvidas para a plataforma desktop.

O Electron por sua vez, é um framework de código aberto que possibilita o desenvolvimento de aplicações desktop utilizando páginas web, isto é possível pois o HTML é executado pelo Node.js e o Chromium, proporcionando a mesma experiência de uma aplicação nativa do sistema operacional. Esta biblioteca é versátil e pode suportar desde páginas web simples, até as soluções mais complexas, com tecnologias reativas como React, Vue.js e Angular. É possível perceber uma grande aceitação desta biblioteca por parte da comunidade de desenvolvimento e até pelas grandes empresas, como a Microsoft que o utilizou para a construção de sua IDE de código aberto chamada Visual Studio Code (ELECTRON, 2020).

A vantagem de utilizar o Electron é que grande parte do código fonte construído no front-end é compatível para ser distribuído como uma aplicação Web, assim o produto desenvolvido com esta tecnologia pode ter mais alcance sem que seja necessário o desenvolvimento específico para cada plataforma (ELECTRON,2020).

Para desenvolvimento do back-end, ou seja, camada que tem como função ser a ponte para a comunicação do banco de dados e a interface gráfica, que também exerce a responsabilidade de aplicar as validações e regras de negócios para atender o problema em 
questão, escolheu-se a linguagem C\# com a versão 2.2 do ASP.NET Core. Este framework é uma versão open-source do ASP.NET, tem a característica de ser multiplataforma e apresenta um grande nível de performance em comparação com as demais tecnologias do mercado (MICROSOFT, 2020).

Com o ASP.NET Core foi desenvolvido uma Web API, na qual a comunicação entre a interface e back-end é realizada através de chamadas REST (Representational State Transfer) que de acordo com Fielding e Taylor (2000) consiste na troca de informações entre computadores utilizando o protocolo HTTP (Hypertext Transfer Protocol). Este processo é chamado de requisição e possui verbos GET, POST, PUT e DELETE que são envoltos em uma série de regras para assegurar a comunicação dos dispositivos em questão.

O PostgreSQL foi selecionado como provedor de banco de dados, pois de acordo com Carvalho (2017), possui um grande nível de segurança, confiabilidade e rapidez no retorno de consultas. $\mathrm{O}$ autor ainda cita que nas pesquisas feitas com desenvolvedores, foi possível identificar uma grande aceitação e satisfação por parte dos usuários.

A comunicação entre o back-end e o banco de dados é realizada por meio do Entity Framework, o qual, segundo Alcaraz (2016), é bem conhecido no mercado de desenvolvimento e possui suporte a diversos provedores de banco de dados.

Para a criação de tabelas do banco de dados foi utilizada uma estratégia presente no Entity Framewok chamada Code First que segundo Alcaraz (2016), refere-se a uma abordagem que consiste na criação de classes Plain Old CRL Objects (POCO). Esta tecnologia possui estruturas simples e são construídas sem vínculos com frameworks ORM. A partir do código desenvolvido, é possível gerar todo o banco de dados e controlar vários aspectos, como configurar nome de tabela, tamanho e obrigatoriedade dos campos, chave primária e estrangeira, dentre outras.

Alcaraz (2016) ainda cita o recurso utilizado no software desenvolvido chamado Migrations, que vem para complementar o Code First, o qual visa controlar as atualizações do banco de dados através das alterações sofridas pelas classes POCO construídas, com ele foi possível registrar as atualizações das diferentes versões do programa. 


\section{APRESENTAÇÃO DE TELAS}

Conforme planejado, foi possível desenvolver uma interface gráfica que integra com a Web API através de chamadas REST, com isso estão acessíveis e funcionais as telas de cadastros de animais, fornecedores, rebanho e os principais manejos de animais.

\subsection{Dashboard}

O dashboard é a tela principal do software, conforme Figura 1, o usuário irá encontrar as principais informações do rebanho, como o total de animais separados por estágio de vida, gráficos que exibam a performance dos ovinos e atalhos para as telas mais utilizadas.

Figura 1 - Tela Dashboard

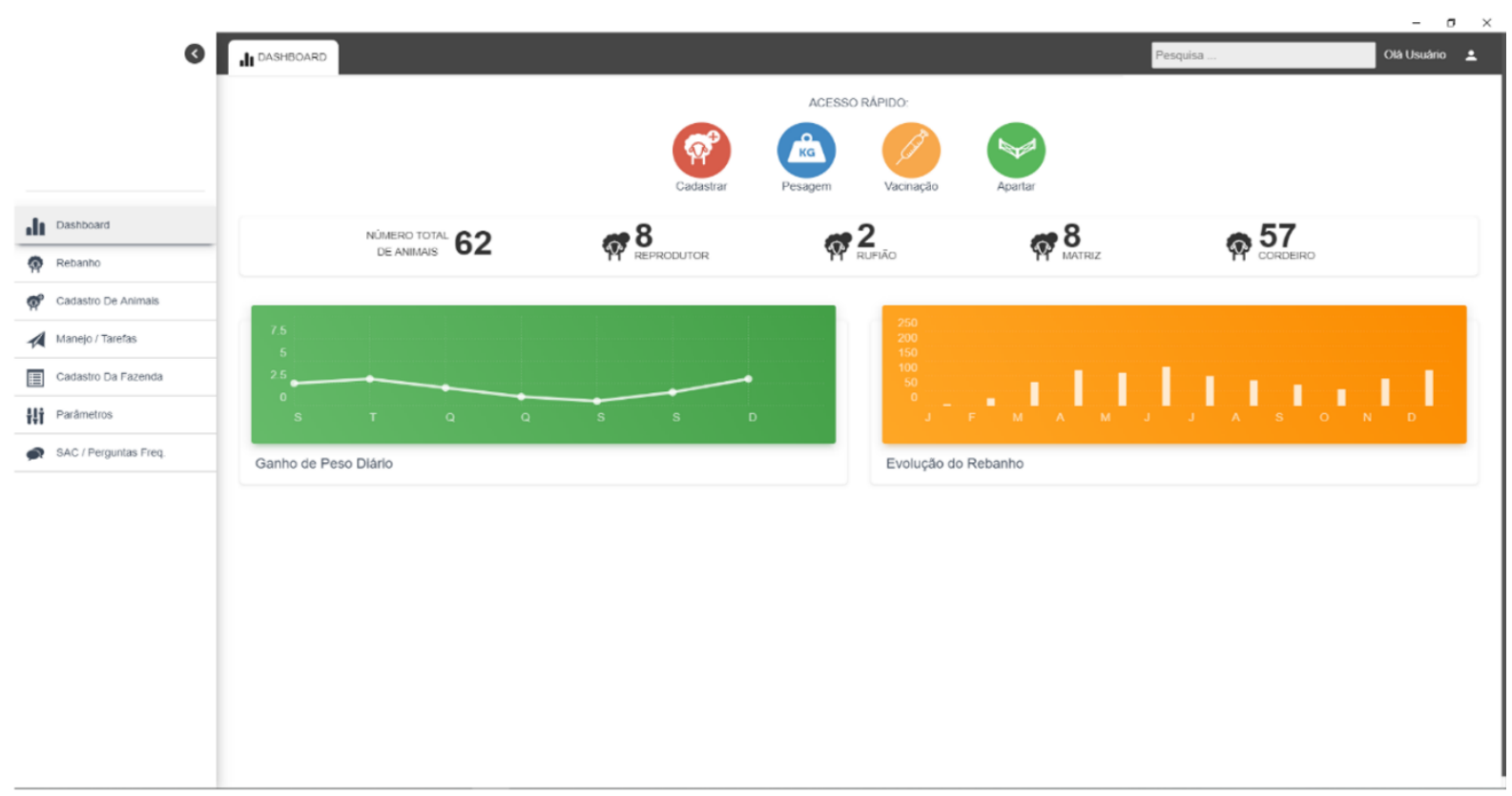

Fonte: Elaborado pelos autores (2020)

\subsection{Cadastro de Animais}

Conforme exemplificado na Figura 2, o cadastro de animais foi separado em duas possíveis origens, sendo compra e nascimento. Esta separação em telas diferentes foi necessária para que o usuário consiga informar dados exclusivos de cada processo. 


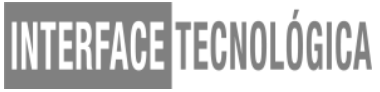

Figura 2 - Tela de seleção de cadastro de animais

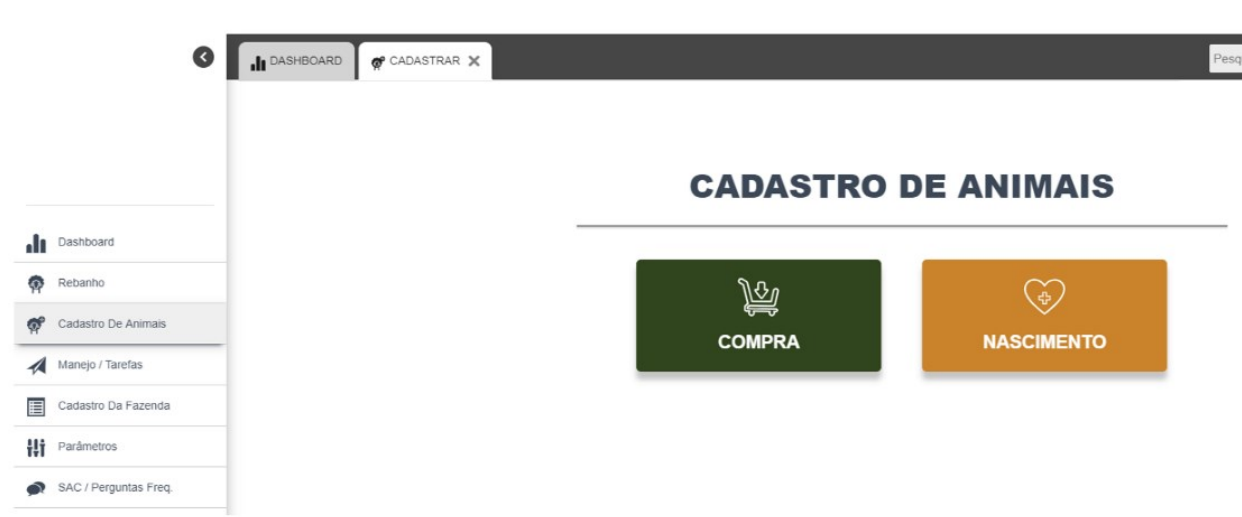

Fonte: Elaborado pelos autores (2020)

O cadastro de compra possui informações pertinentes ao animal que está sendo adquirido, como a tag de identificação, data da compra, sexo, fase da vida, fornecedor, dentre outras informações presentes na Figura 3.

Figura 3 - Tela Cadastro de Compra

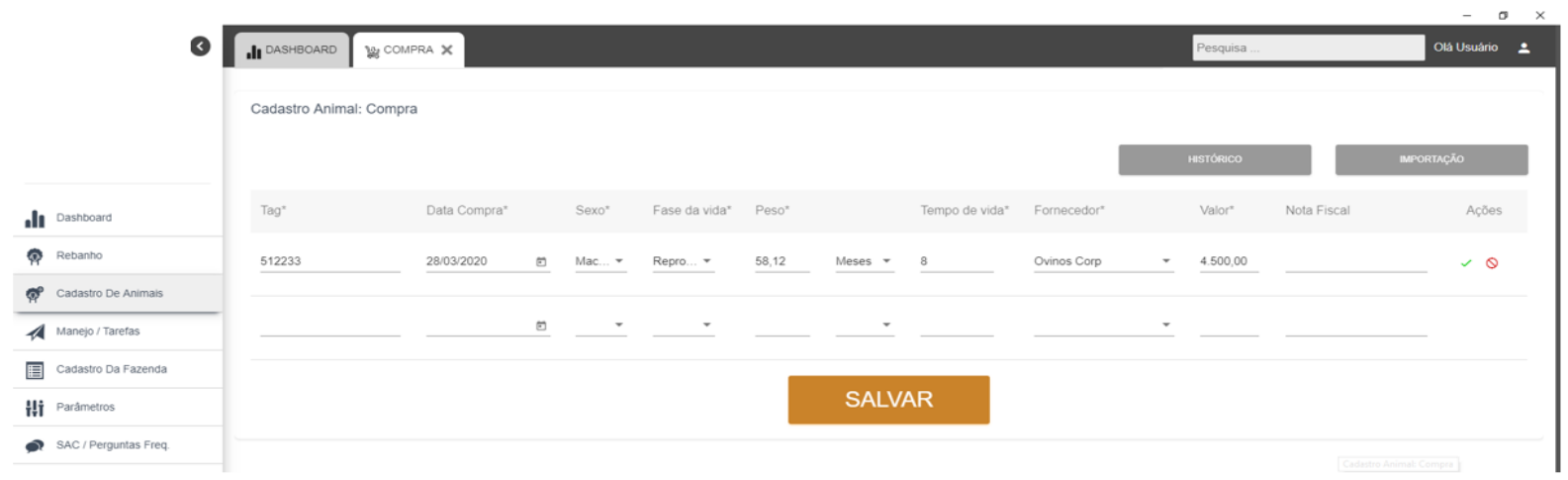

Fonte: Elaborado pelos autores (2020)

A figura 4 apresenta o cadastro de nascimento, que tem como objetivo coletar as principais informações sobre o cordeiro, que incluí informar a tag de identificação, data do nascimento, sexo, peso, tag de mãe, peso da mãe após o parto e identificar o pai. 
Figura 4 - Tela Cadastro de Nascimento

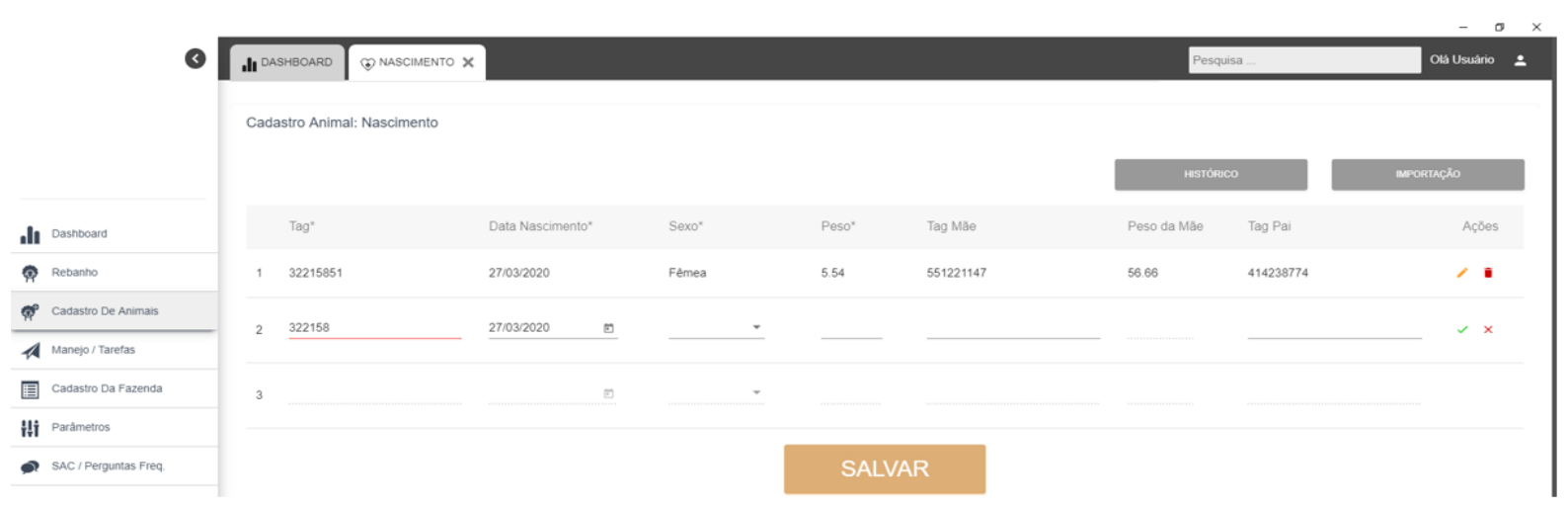

Fonte: Elaborado pelos autores (2020)

\subsection{Rebanho}

A tela chamada rebanho foi desenvolvida com o propósito de ser um relatório dinâmico, que pode ser utilizada para várias finalidades, como na seleção dos melhores animais para venda, identificação das melhores matrizes ou reprodutores para uma estação de monta.

Figura 5 - Tela Rebanho

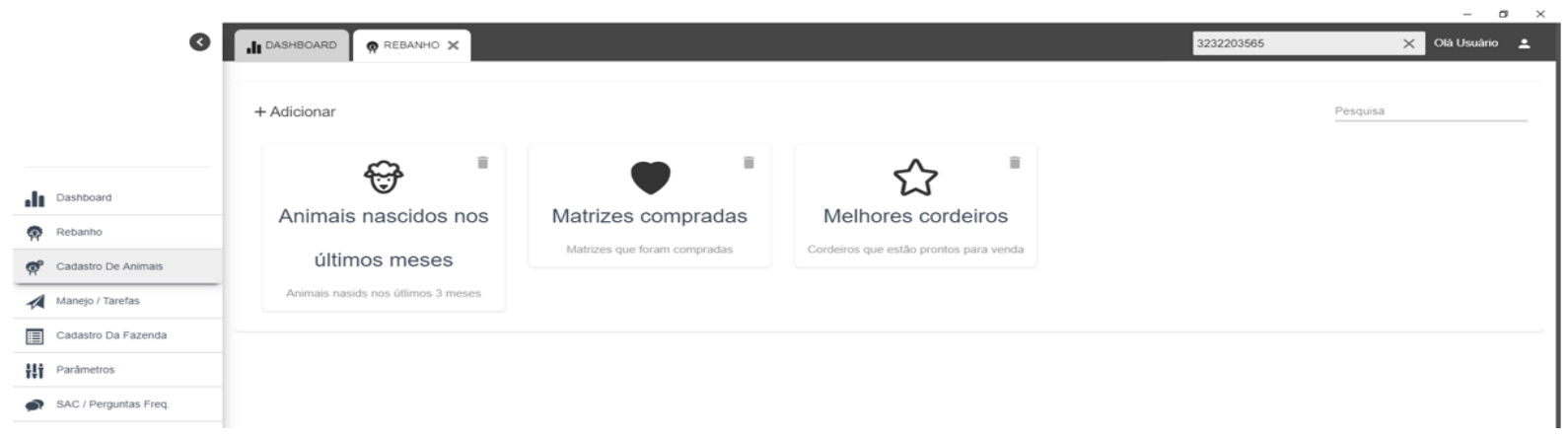

Fonte: Elaborado pelos autores (2020)

Após abrir a aplicação, são apresentadas as visões de rebanhos, ou seja, os relatórios configurados pelo o usuário. Ao selecionar o item desejado ou clicar no recurso "Adicionar" exibido na Figura 5, o relatório é apresentado conforme Figura 6, nesta etapa é possível informar o nome, descrição, ícone, além de editar e incluir novas colunas e filtros para atender as necessidades do usuário. 
Figura 6 - Tela Edição do Rebanho

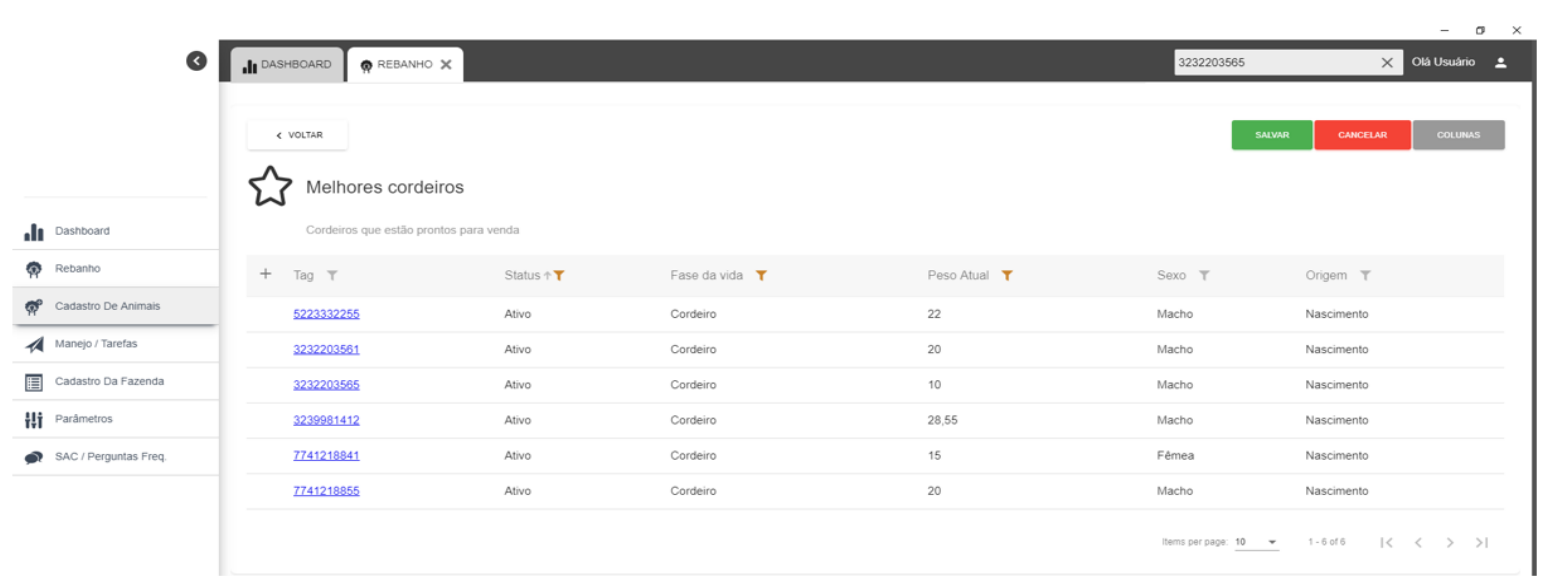

Fonte: Elaborado pelos autores (2020)

\subsection{Manejo de Animais}

O manejo de ovinos é envolto por vários processos que buscam registrar a evolução do rebanho, bem como os cuidados com ele, como pesagem, vacinação, desmama, incorporação, venda, morte, dentre outros. Assim como apresentado na Figura 7, estas aplicações foram desenvolvidas pois representam as principais informações referentes aos animais produzindo dados essenciais para realizar a extração de índices que auxiliam na gestão do negócio.

Figura 7 - Tela Seleção de Manejos

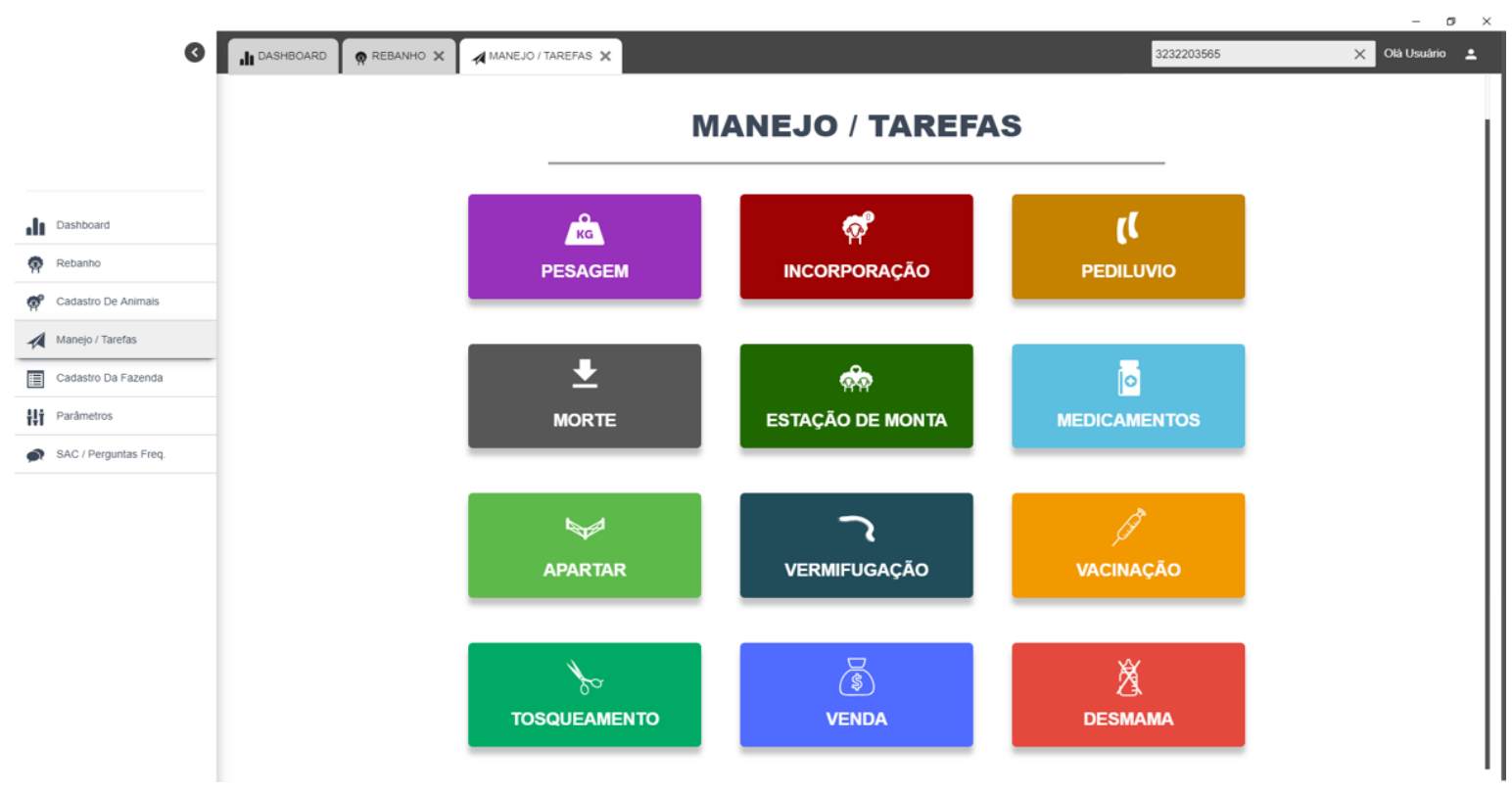

Fonte: Elaborado pelos autores (2020) 


\section{CONSIDERAÇÕES FINAIS}

Este artigo elucidou o processo de desenvolvimento de um software que caminha para tornar-se uma ferramenta de gestão na criação de ovinos, com destaque na usabilidade para o produtor rural. Ao longo do estudo do cenário da ovinocultura, foi possível embasar melhor o conhecimento e a compreensão do mercado, aspecto fundamental para a criação de um produto que atenda às necessidades de forma proveitosa. De acordo com as carências do ovinocultor, foi tomada a decisão de quais tecnologias seriam mais apropriadas e melhor se adequariam ao perfil dos usuários, proporcionando recursos que cumpram e atendam à demanda.

O software desenvolvido possibilita a rastreabilidade destes animais, auxilia nas tomadas de decisões, como a redução de custos e o aumento da produtividade. Além disso, influencia na qualidade de todo o rebanho através do controle de doenças e na gestão do processo de reprodução.

Em trabalhos futuros, será abordada a implementação e testes em produtores de animais ovinos $^{2}$, possibilitando identificar os acertos e pontos de melhoria em relação ao produto planejado, do mesmo modo que, por meio de feedback do usuário final, detectar a necessidade de acréscimo de novos recursos.

\section{REFERÊNCIAS}

ALCARAZ, Paulo Cesar Fernandez. Entity Framework, uma introdução ao ORM utilizando o Code First, 2016. Trabalho de Conclusão de Curso (Tecnologia em Análise e Desenvolvimento de Sistemas) - Universidade Tecnológica Federal do Paraná, Medianeira, 2016. Disponível em: <http://repositorio.roca.utfpr.edu.br/jspui/handle/1/15181>. Acesso em: 27 de março de 2020.

ALVES, Willian Pereira. Desenvolvimento de aplicações web com angular 6. Rio de Janeiro: Alta Books, 2019.

BELLENZIER, Marina. Um estudo sobre a relação da adoção do método ágil scrum com a produtividade em equipes de desenvolvimento de software. PUCRS, Porto Alegre, 2017. Disponível em: <http://tede2.pucrs.br/tede2/handle/tede/7746>. Acesso em: 21 de março de 2020.

CARVALHO, Vinícius. PostgreSQL: Banco de dados para aplicações web modernas. Casa do Código, 2017.

\footnotetext{
${ }^{2}$ De acordo com o cronograma deste projeto, as fases de implementação e testes foram interrompidas devido as exigências do distanciamento social imposto pela pandemia do COVID-19 em março de 2020.
} 
ELECTRON, Build cross-platform desktop apps with JavaScript, HTML and CSS, 2020. Disponível em: <https://www.electronjs.org $>$. Acesso em: 27 de março de 2020.

FIELDING, R. T.; TAYLOR, R. N. Architectural styles and the design of network-based software architectures, University of California, Irvine Doctoral Dissertation, 2000.

IBGE - Instituto Brasileiro de Geografia e Estatística. Pesquisa Pecuária Municipal: total efetivo de ovinos de todos os estados, 2018. Disponível em: $<$ https://sidra.ibge.gov.br/tabela/3939>. Acesso em: 30 de maço de 2020.

LIRANI, Antonio Carlos. Rastreabilidade na cadeia produtiva das carnes caprinas e ovinas. $3^{\circ}$ Simpósio Internacional sobre Caprinos e ovinos de Corte $-3^{\circ}$ SINCORTE, João Pessoa, Paraíba, Brasil, 2007. Disponível em: $<$ http://revistatca.pb.gov.br/edicoes/volume-022008/volume-2-numero-3-setembro-2008/tca10_rastreabilidade.pdf $>$. Acesso em: 16 de fevereiro de 2020.

MICROSOFT, What is ASP.Net Core? Disponível em: $<$ https://dotnet.microsoft.com/learn/aspnet/what-is-aspnet-core $>$. Acesso em: 27 de março de 2020 .

RAINERI, C. et al. As inovações tecnológicas na ovinocultura brasileira e seus efeitos na organização do sistema agroindustrial. PUBVET, Londrina, V. 7, N. 21, Ed. 244, Art. 1614, $2013 . \quad$ Disponível em: $<$ http://www.pubvet.com.br/uploads/4fc49c27a17aba019cd2971e783a775c.pdf $>$. Acesso em: 05 de abril de 2020.

SEBRAE - Serviço Brasileiro de Apoio às Micro e Pequenas Empresas. Manejo Básico de Ovinos C Caprinos, 2009. Disponível em: $<$ https://www.caprilvirtual.com.br/Artigos/ManejoBasicoOvinoCaprinoSebrae.pdf $>$. Acesso em: 20 de janeiro de 2020.

TERLIZZI, Marco Alexandre. BIANCONLINO, César Augusto. Projeto de Software no Setor Bancário: Scrum ou Modelo V. Tecnologias de Administração e Contabilidade, 2014. Disponível em: <http://www.spell.org.br/documentos/ver/32124/projeto-de-softwareno-setor-bancario--scrum-ou--->. Acesso em: 21 de março de 2020.

VIANA, João Giaribaldi Almeida. Panorama Geral da Ovinocultura no Mundo e no Brasil. Revista Ovinos, Ano 4, $\mathrm{N}^{\mathrm{o}}$ 12, Porto Alegre, março de 2008. Disponível em: $<$ https://www.researchgate.net/profile/Joao_Viana7/publication/228460370_Panorama_geral_ da_ovinocultura_no_mundo_e_no_Brasil/links/5614495808ae983c1b406e66/Panoramageral-da-ovinocultura-no-mundo-e-no-Brasil.pdf $>$. Acesso em: 20 de janeiro de 2020. 